\title{
Evaluation of Going Global in the "Theoretical Framework for Evaluating POA-Based Teaching Materials"
}

\author{
Yinghua $\mathrm{Gu}^{1} \&$ Jia Suo ${ }^{1}$ \\ ${ }^{1}$ English Department, North China Electric Power University, Baoding, China \\ Correspondence: Yinghua Gu, English Department, North China Electric Power University, Baoding, China.
}

Received: October 29, 2021

Accepted: December 18, 2021

Online Published: January 20, 2022

doi:10.5539/ies.v15n1p177

URL: https://doi.org/10.5539/ies.v15n1p177

\begin{abstract}
Oriented by the theoretical framework for evaluating POA-based materials, this paper aims to evaluate Going Global from three dimensions: appropriate productive objectives, effective enabling activities and successful attainment of productive objectives by collecting interview data of six teachers, questionnaire of students and students' works. The results show that Going Global embodies the concept of POA textbook evaluation. It has the following advantages: each unit set appropriate productive objectives which help students to have clear mind about what they need do in the unit learning; the textbook provides various related input materials and task types to assist students' accomplishment of unit objectives; the teaching material itself stimulates students' interest and enhances the internal driving force of students' study. The possible disadvantage is that the gradual progress of the difficulty among the units in the same level textbooks still needs to be improved. In addition, the teaching material is deficient in the cultivation of basic language skills, and lacks relevant language training, which needs further improvement.
\end{abstract}

Keywords: theoretical framework, evaluation, criteria

\section{Introduction}

Teaching material can defined from broad sense and narrow sense. Broadly speaking, any material that is beneficial to learners' knowledge growth or skills development can be called teaching materials. However, in a narrow sense, teaching materials only refer to textbooks. This paper will discuss it from the narrow sense.

Teaching material is the main carrier of teaching content and the basic guarantee to achieve teaching goal. The same is true of college English textbooks. College English textbooks are not only reference books for teachers to organize teaching activities, but also important resources for students to input language and complete learning tasks. Choosing excellent English textbooks is very important for realizing teaching goals. Therefore, attention should be paid to the evaluation of textbooks. From the statistics of 2000-2019 (see Table 1) (Wei \& Wang, 2020), the analysis of university English teaching materials by domestic scholars is mostly internal evaluation (79.3\%), the external evaluation and the combination of internal and external evaluation accounting for $13.8 \%$ and $6.9 \%$, respectively.

Table 1. Statistics of the evaluation of textbooks in 2000-2019

\begin{tabular}{ccccccc}
\hline \multirow{2}{*}{ Evaluation pattern } & \multicolumn{7}{c}{ Year } \\
\cline { 2 - 7 } & $2000-2004$ & $2005-2009$ & $2010-2014$ & $2015-2019$ & Total articles & Percentage \\
\hline Internal evaluation & 10 & 11 & 15 & 10 & 46 & $79.3 \%$ \\
External evaluation & 2 & 2 & 2 & 2 & 8 & $13.8 \%$ \\
Combination & 1 & 1 & 2 & 0 & 4 & $6.9 \%$ \\
\hline
\end{tabular}

And the evaluation of teaching materials by domestic scholars mainly focus on the text difficulty, language elements, such as vocabulary re-emergence mode (Zhu \& Xu, 2014), vocabulary coverage (Zheng, 2012), or static evaluation of the overall composition of textbooks or unit composition. For example, Evaluation of "Contemporary College English" Based on Cunningsworth Evaluation Framework (Hu, 2017) mainly analyzes the overall difficulty and unit composition of the textbooks; Xu \& Xiao (2011)'s Analysis of "Contemporary College English Intensive Reading" Based on Cunningsworth Evaluation Framework involves the learning theory 
showed in the textbook, the content, the subject and the genre of text, etc. Moreover, these studies ignore the voice of teachers and students, the main body of the use of teaching materials, that is, fails to carry out dynamic research on teaching materials from the perspective of teachers and students. In addition, many domestic studies are using foreign teaching materials evaluation framework to evaluate domestic teaching materials. But based on the local teaching material evaluation system evaluating domestic teaching materials is rare.

\section{Concept Definition and Theoretical Framework of "Production-Oriented Approach"}

\subsection{Internal and External Evaluations}

Internal evaluation refers to evaluating the scientificity, rationality and effectiveness of teaching materials, mainly from the aspects of foreign language teaching ideas, teaching objectives, teaching methods, teaching contents, various components of teaching materials, design forms of teaching materials, and applicable scope and objects of teaching materials.

External evaluation is to evaluate whether a textbook is suitable for a specific user group. It mainly evaluates from three aspects: curriculum standards, teachers' teaching needs and students' learning needs (Cheng, 2002).

\subsection{Theoretical Framework for Evaluating POA-Based Teaching Materials}

\subsubsection{POA-Based Teaching Materials}

POA is short for Production-oriented Approach. POA-based teaching materials refer to the textbooks are compiled based on the POA theory.

\subsubsection{Theoretical Framework for Evaluating POA-Based Teaching Materials}

Wen (2017)'s “Theoretical Framework for evaluating POA-based teaching materials" puts forward three criteria for the effectiveness of teaching materials: 1) appropriate productive objectives; 2) effective enabling activities; 3 ) attainment of productive objectives. Each criterion has 3-4 measurement indicators (see Figure 1). These three criteria take the setting of the output target as the starting point and the realization of the output target as the end point, which is a closely related organic whole. This theory regards teaching materials as a dynamic process, rather than a rigid book. The first standard and the second standard are from the perspective of teachers; the third standard is from the perspective of students. The three organic components of the theoretical framework not only take into account all direct users' perspectives, but also combine the internal evaluation and external evaluation of teaching materials.

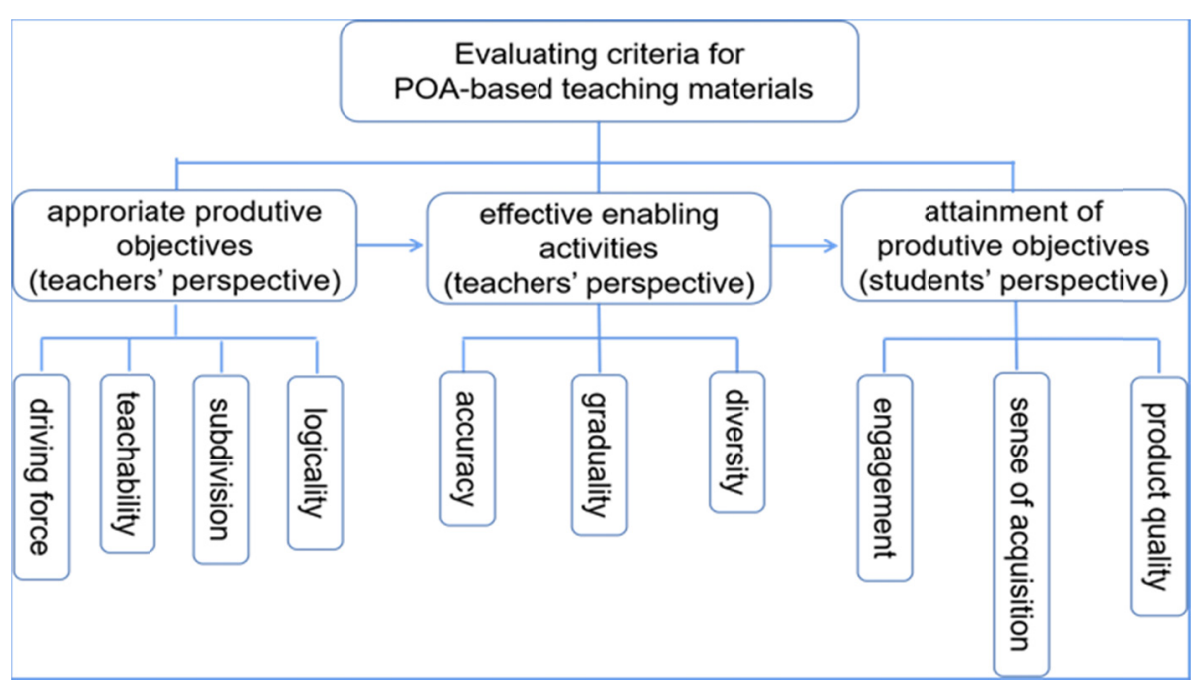

Figure 1. Theoretical framework for evaluating POA-based teaching materials

\section{Design of the Study}

\subsection{Target Textbook}

The target textbook of this study is Going Global, which is compiled based on POA concept. The textbook is divided into two levels: elementary and intermediate. Each level is set as a different main character, and the 
workplace scene is designed according to the real workplace tasks encountered by the main characters in their work. In addition, the protagonist's design follows the law of career development, and the position increases step by step. Through the change of characters' positions, students understand that different positions require different core competencies to complete different workplace tasks.

\subsection{Research Issues}

The purpose of this study is to explore whether Going Global meets the evaluation criteria. Research questions include:

1) Does Going Global conform to the textbook evaluation standard of "appropriate productive objectives"?

2) Does Going Global conform to the textbook evaluation standard of "effective enabling activities"?

3) Does Going Global conform the teaching material evaluation standard of "attainment of productive objectives"?

\subsection{Research Target and Research Method}

\subsubsection{Research Target}

The interviewees are freshmen from non-English major,with about 750, and six English teachers who apply Going Global in class of our school, represented by T1, T2, T3, T4, T5 and T6 respectively. Both students and teachers are from the same school with the researcher. Table 2 shows the basic information of teachers interviewed.

Table 2. Background information of interviewees

\begin{tabular}{ccccc}
\hline Teacher & Gender & Academic degree & Professional title & Working years \\
\hline T1 & female & master & associate professor & 16 \\
T2 & female & master & lecturer & 9 \\
T3 & female & master & lecturer & 16 \\
T4 & male & doctor & associate professor & 21 \\
T5 & female & doctor & lecturer & 2 \\
T6 & female & master & associate professor & 19 \\
\hline
\end{tabular}

\subsubsection{Research Method}

For teachers, this research adopts semi-structured interview method. The interview questions roughly include four parts: background information of teachers, macro evaluation of teaching materials, evaluation questions related to "appropriate productive objectives" and "effective enabling activities", and open questions.

Structured questionnaires and works analysis are adopted for students. The questionnaire focuses on two dimensions of students' engagement and sense of acquisition. The works analysis concentrates on the dimension of product quality.

See Appendix A and Appendix B for specific interview questions and questionnaire.

\subsection{Data Collection and Collation}

For teachers, one-on-one interviews are conducted for about one hour. After the interview, the researcher first sorts out the interview data. In order to ensure the accuracy of the interview content, the researcher returns the edited excerpts of interview data to the interviewee for reconfirmation. Secondly, the researcher compares the confirmed interview data with the measurement indicators under the two dimensions of "appropriate productive objectives" and "effective enabling activities", and analyzes and interprets the data accordingly. Finally, draw a conclusion based on the data analysis.

For students, after the questionnaire and the collection of works, the researcher firstly classifies and counts the collected questionnaire data through data statistics software and sort out the students' works. Secondly, the researcher analyzes and interprets the above data according to the measurement indicators under "attainment of productive objectives". Finally, draw a conclusion based on the data analysis.

\section{Discussion}

\subsection{Evaluating Going Global from the Perspective of "Appropriate Productive Objectives"}

\subsubsection{Driving Force}

"Driving force" refers to the strength stimulating students' desire to learn (Wen, 2017). All the six teachers 
interviewed indicated that Going Global has great driving force and can stimulate the teaching/learning willingness of teachers and students. First, the output tasks and learning objectives in this book are set in real and specific workplace a situation, which helps students understand their own shortcomings in the process of workplace communication and motivates students' learning. Second, the unit firstly presents a real case. Based on the case, the objective is clearly defined, which facilitates teachers and students to better understanding their tasks in this unit.

Wen (2017) also points out that to judge the driving strength of the textbook, it is necessary to examine the driving means and content adopted in it. All teachers interviewed acknowledge that Going Global has strong driving strength because it involves various driving means and diverse cognitive contents with the features of high-order, innovation and challenging.

On the one hand, the task design adopts a multi-modal approach, including videos (scanning QR code) regarding celebrity interviews, user surveys, conference discussions, superior-subordinate communication, business visits, business presentations, etc., and texts of different genres, such as company profiles, celebrity introductions, user survey feedback, research reports, business plans, meeting minutes, business emails, project plans, etc. In addition, it is equipped with listening and speaking practice audio (scanning QR code), pictures and tables for assisting task completion, etc., as shown in Figure 2.

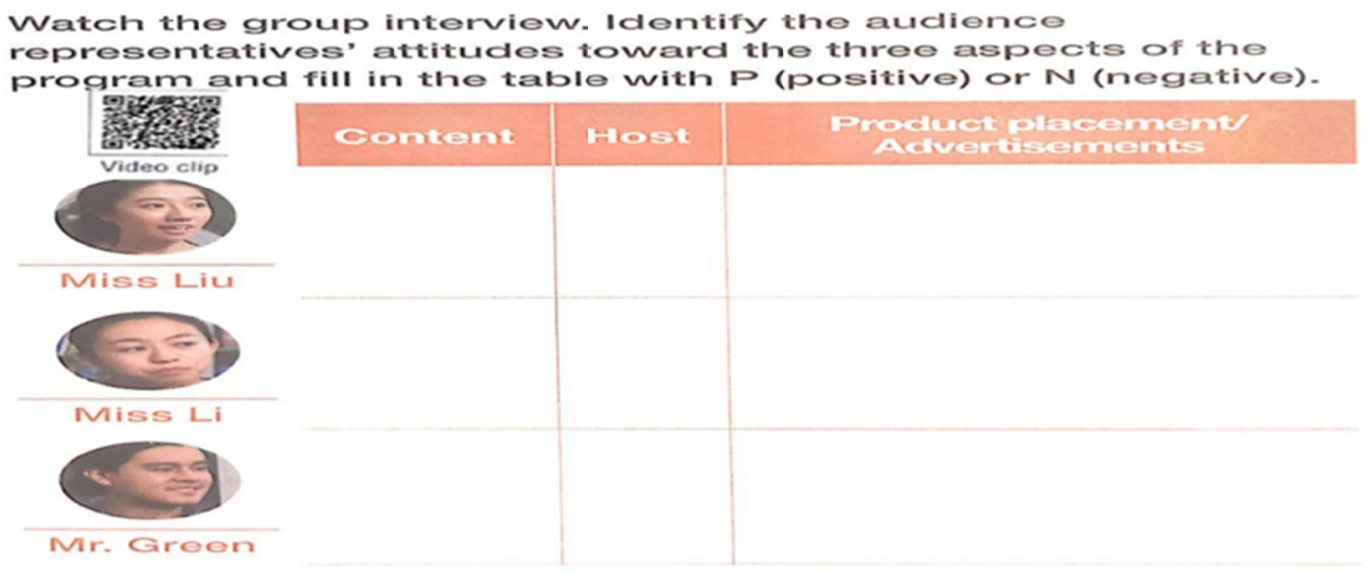

Figure 2. Unit 3 task design 1 in Going Global

Three of the teachers interviewed said:

To complete this task, we need to scan the QR code to watch the video. Through the communication of the characters in the video, we can understand their views, and then complete the related exercise. The video is presented in the form of dialogue, and the exercise is displayed in a chart mode, with the heads of characters in the play, which provides students with a sense of reality. Watching, listening, thinking, writing, all these means combine to stimulate students'senses in multiple dimensions, thus improving learning efficiency.

On the other hand, the teaching materials are rich in content, covering humanities, social sciences and other fields, including challenging and high-level contents such as artificial intelligence, big data and virtual simulation, which are at the forefront of science and technology, and more time-sensitive contents such as exotic folk culture and popular culture. These contents can guide teachers and students to pay attention to social hot topics. And task design is challenging because of novel topics, which encourages students to expand their existing knowledge reserves and effectively solve the teaching dilemma of "platitudes". T2 and T6 both represent:

Both teachers and students think the content make them feel fresh and help them keep up with the trend. For example, the first unit, equipped with a POS machine to scan the two-dimensional photos of WeChat for payment, launches an argument on the advantages and disadvantages of the current payment method: cash payment or mobile payment. . They are all things that teachers and students can't live without in their daily life. Both teachers and students have more ideas. Students are willing to talk more, and we are easy to comment.

Moreover, under the background of telling Chinese stories well, Chinese native elements are also integrated into 
the textbooks. For example, Chen Ming, the main character in the elementary level, Amy Li and Wang Wei, the main character in the intermediate level are all Chinese. Those interviewed on behalf of foreign companies are also Chinese; the tasks involved in the design revolve around Beijing Opera, the quintessence of Chinese culture, or tourist cities in China, all of which make students have a strong sense of substitution. T1 believes that:

In the future, a large number of students will either work in Chinese enterprises, which may involve handling business with foreigners, or work in foreign enterprises, which will involve working with English-speaking colleagues. And now the national Belt and Road Strategy needs more international compound talents with feelings of home and country. So although it is an English textbook, it can't be all foreign things. It must have domestic things. Students are also motivated to participate because of their familiarity.

The localization of the design of teaching materials should be based on the principle of "the object target learners are the local; the input materials are integrated with the local features; the output tasks serve the local; and the distance between the teaching content and the teaching object should be shorten (Jia \& Shen, 2020)", so as to stimulate students' interest in learning and enhance the driving force of teaching materials.

\subsubsection{Teachability}

Teachers interviewed all think although Going Global involves difficult fields such as business, science and technology, it doesn't use obscure professional vocabulary, and many contents are closely related to Chinese native land and students' daily life, so students are relatively easy to master. The goal of the textbook is also in line with students' English level, and the content of the textbook can be basically completed within the time specified by the school, so the textbook is highly teachable.

However, because the textbook focuses on cultivating students' communication ability and problem-solving ability, and the designed tasks are mostly real workplace tasks, teachers worry that they will not suitable for students who have accepted traditional English for a long time. However, after some observation, it is found that the students do not know how to start at beginning, but after a period of study, they basically respond well.

\subsubsection{Subdivision and Logicality}

Wen (2017) thinks that "subdivision" means that the produced target needs to be refined into series subheadings. "Logicality" means that the series subheadings that have been refined can be shaped into an subheading chain with internal logic. Going Global includes four cases, presenting four real workplace tasks, which are the four overall goals. Each case has two units which are the two steps to accomplish the overall goal. Either unit has its own sub-goal, and includes five sections: Starting up, Taking in, Building up, Carrying out and Looking beyond. Starting up is a "driving" step, presenting workplace situations, defining output tasks and learning objectives, and stimulating students' learning motivation. Taking in and Building up are the "facilitating" links, which cultivate students' communication ability, problem analysis and problem solving ability through information acquisition and skill construction. This part serves the driving link. Carrying out is an "evaluation" step. In this stage, students comprehensively apply what they have learned to realize the output. This part is the detection of the first two parts. Looking beyond is a field of vision expansion, which provides different forms of materials related to the theme of the unit to cultivate students' core competence and enhance their humanistic quality. All the five plates interlock with each other to sever for arriving at the sub-goal. The overall structure of each case and the function of each plate and their relations in each unit are shown in Figure 3. 


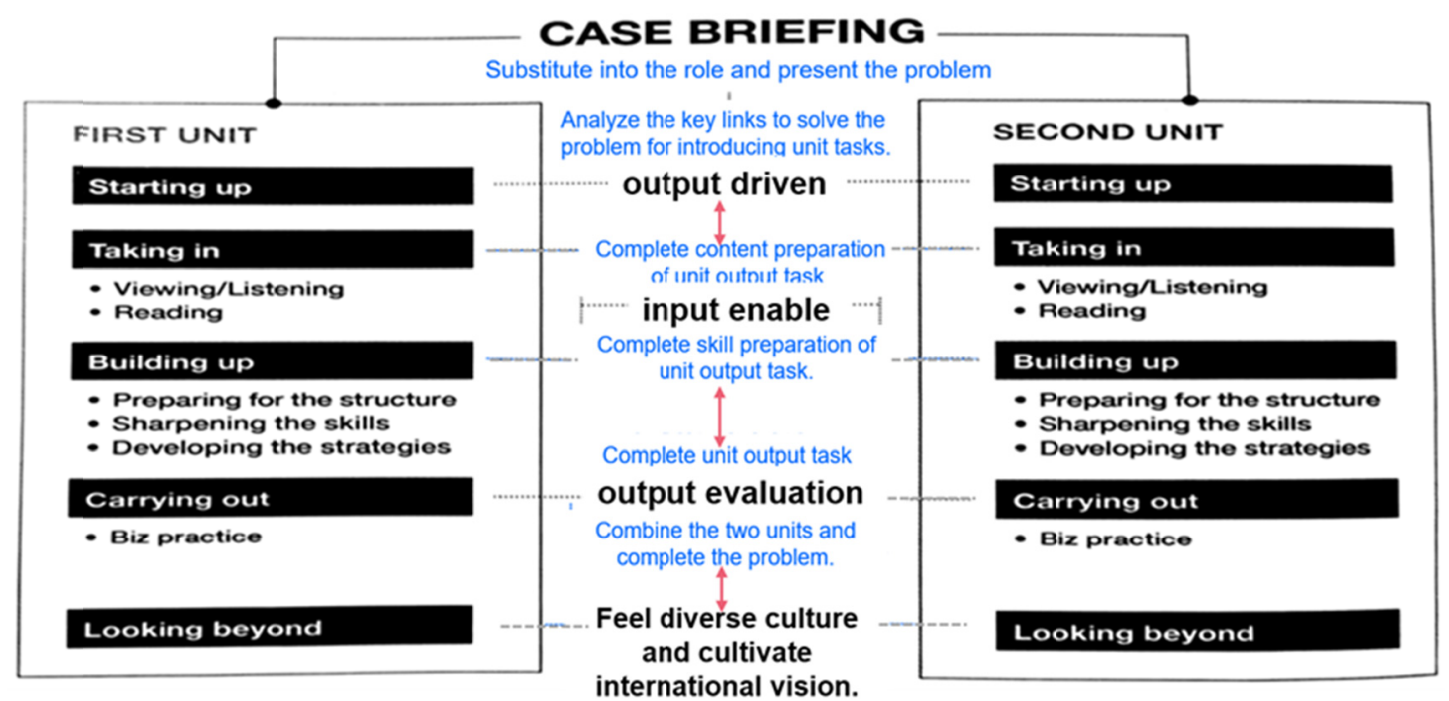

Figure 3. Going Global unit design

In addition, the specific design of each case's goal also reflects strong logicality. T6 cited the first case as an example:

The overall goal of the first case is to select sponsoring partners. This goal is divided into two sub-goals: first, the company information report, and second, the arrangement of field visits. These two goals are accomplished in two units respectively. Each sub-goals is subdivided into several small goals. Take the first sub-goal as example. Below the sub-goal, it lists 5 small goals:1) get the general information about a company from various sources; 2) get familiar with the two structures of a comparison report. 3) use transitional words and expressions to make comparison and contrast; 4) use tenses correctly when presenting different information; 5) present information about the companies by making comparisons. Students gradually complete the study of each case in the order of "small goals-sub-goals-overall goals". These teaching objectives are gradual, well subdivided and logical, which make the whole case a complete relational framework and ensure the effective completion of output tasks.

\subsection{Evaluating Going Global from the Perspective of "Effective Enabling Activities"}

\subsubsection{Accuracy}

Most teachers think that this textbook can effectively promote task output. T3 thinks that the Building up section in the textbook contains three parts: preparing for the structure, sharing the skills and Developing the strategies, which provide the discourse skills needed to complete the unit output task from three aspects: discourse structure, language skills and communication strategies, and can effectively help students to construct the necessary skills and strategies to complete the unit output task. T2 emphasizes the Sharpening the skills in particular. It is considered that this part provides not only the written and oral expression skills needed to complete the unit output task, but also various activities involving skills and explanations of these skills. Students explore and discover skills through activities, and then reflect on the skills with reference to skills explanations, and finally internalize them into their own language skills, improve their language application ability, and prepare for the completion of unit output tasks.

However, some teachers question the part of Sharpening the skills, and think that the lack of more detailed explanation of skills and insufficient input of language materials for training language skills will affect students' language skills mastering, which further influences their completing sub-goals to a certain extent. For example, "using persuasive techniques in a program introduction" on page 79 only allows students to understand "persuasive techniques" through a matching exercise, without further explanation, and the training of this skill only provides five sentences, as shown in Figure 4. 
2 The following are some techniques that can be used when you want to persuade people in communication. Work in pairs and match the techniques with their corresponding functions.

\begin{tabular}{|c|c|c|}
\hline Techniques & & Functions \\
\hline $\begin{array}{l}1 \text { Using colorful language } \\
\text { like adjectives }\end{array}$ & & To include the person in the same group \\
\hline $\begin{array}{l}2 \text { Using evidence like facts } \\
\text { and figures }\end{array}$ & B & $\begin{array}{l}\text { To create a memorable image and to catch } \\
\text { interest }\end{array}$ \\
\hline $\begin{array}{l}3 \text { Using inclusive language } \\
\text { like "we", "our" and "us" }\end{array}$ & C & $\begin{array}{l}\text { To provide rational scientific proof as the basis } \\
\text { for points of view }\end{array}$ \\
\hline 4 Using rhetorical questions & $\mathbf{D}$ & To help lead people to a particular conclusion \\
\hline 5 Using reasons and logic & $\mathbf{E}$ & To show the mood or feeling of the language \\
\hline 6 Using different tones & $\mathbf{F}$ & $\begin{array}{l}\text { To link ideas and develop arguments supporting } \\
\text { points of view }\end{array}$ \\
\hline
\end{tabular}

3 Work in pairs and rewrite the following sentences using the persuasive techniques in Activity 2.

1 It's time to stand up and show support for our culture.

2 Your participation would be appreciated by the viewers.

3 Your participation would add value to the program.

4 You can make some contributions to the industry.

5 Ethnic traditions should be protected.

Figure 4. Unit 3 task design 2 in Going Global

\subsubsection{Graduality}

All the teachers interviewed think that from the whole series, the textbook has a good gradualism, which is reflected in the fact that the design of characters in the textbook follows the law of career development, and the positions increase step by step, from junior management trainees to intermediate product managers. With the promotion of the position, the difficulty of the tasks to be completed is gradually increasing. From the single textbook, the process of completing each case task is also step-by-step. These steps interlock with each other,with small goals serving sub-goals, and then contributing to the realization of the ultimate goal.

However, there is no obvious increasing trend in the difficulty among the four cases in the textbook at the same level. T3 and T6 think that:

Taking the elementary level as an example, I feel that there is a parallel relationship between each case, which seems to have neither the improvement of language skills nor the improvement of task completion. Presumably, the editor's criteria for dividing case are based on the types of tasks that may be faced by new management trainees.

The researcher thinks that the different units in the same textbook should have a certain degree of advancement in difficulty. The textbook could gradually increase the difficulty of activities to help students achieve advanced output (Qiu, 2017).

\subsubsection{Diversity}

The diversity of the textbook is mainly reflected in four aspects: 1) multilevel teaching objectives; 2) various driving means; 3) sufficient content; 4) manifold types of task design. There have been the relevant discussions about the first three aspects under the dimension of "appropriate productive objectives" in the preceding paragraphs, so they will not be repeated here. With respect to the fourth aspect, T1 indicates: 
The teaching material designs various tasks. For example, from "writing" aspect, it includes writing business proposals, drafting letters and replying emails; from "listening" aspects, it provides audios and videos about interviews, topic discussions and business negotiations. The completion of tasks often requires the cooperation of listening, speaking, reading, writing and translating skills, which effectively solves the separation of listening, speaking, reading, writing and translating in traditional teaching.

\subsection{Evaluating Going Global from the Perspective of "Attainment of Productive Objectives"}

\subsubsection{Engagement and Sense of Acquisition}

Through the analysis of questionnaire data (see Table 3), it is found that most of students are satisfied with the textbook. $58 \%$ of the students think that the compilation of the textbook greatly encourages their participation in the classroom, and $60 \%$ and $56 \%$ of the students who believe that they have acquire a lot from the study of each unit and the study of the whole textbook, respectively. In addition, about $30 \%$ of the students think that it is more interesting than the traditional textbook even if they do not get such a high sense of accomplishment.

Table 3. Questionnaire result

\begin{tabular}{cccccc}
\hline \multirow{2}{*}{ Indicator } & \multirow{4}{*}{ Question } & \multicolumn{4}{c}{ Percentage (\%) } \\
\cline { 3 - 6 } & & $\mathrm{A}$ & $\mathrm{B}$ & $\mathrm{C}$ & $\mathrm{D}$ \\
\hline \multirow{2}{*}{ engagement } & 1 & 51 & 30 & 15 & 4 \\
\multirow{3}{*}{ sense of acquisition } & 2 & 58 & 25 & 14 & 3 \\
& 3 & 60 & 30 & 8 & 2 \\
& 4 & 56 & 32 & 10 & 2 \\
\hline
\end{tabular}

\subsubsection{Product Quality}

According to the completion of students' works, most students can complete the unit task output satisfactorily, which fully reflects that the real business background and future professional experience in Going Global stimulate students' thirst for knowledge. Students perceive the workplace situation and the skills they need to learn from the external environment and internal mood, gain experience and sentiment through full participation, and gain growth through experience.

\section{Conclusion}

This survey shows that Going Global embodies the concept of POA textbook evaluation, and the textbook has great driving strength. The teaching goals are classified into logical sub-goals. At the same time, the input materials accurately reflect productive objectives. The textbook provides multilevel teaching objectives, various driving means, sufficient input materials and manifold types of task. The series of teaching materials have clear increasing trend in difficulty. The teaching material itself stimulates students' interest and enhances the internal driving force of students' study.

The disadvantage is that the gradual progress of the difficulty among the units in the same level textbooks still needs to be improved. In addition, the teaching material is deficient in the cultivation of basic language skills, and lacks relevant language training, which needs further improvement.

This study has the following two implications for textbook evaluation:

First, the criteria for evaluating the effectiveness of POA textbooks provide a local theoretical framework for the evaluation of local college English textbooks.

Second, the compilation, use and evaluation of teaching materials should be integrated. The purpose of textbook evaluation is not to grade textbooks, but to better serve the compilation and the use of textbooks. The evaluation results should be fed back to the editors of relevant teaching materials. Textbook writers should pay full attention to the deficiencies in the evaluation results of textbooks and improve them, so as to improve the compilation of textbooks in an all-round way. These writers also need to integrate the advantages into the future reprint or compilation of teaching materials. The evaluation results should also be fed back to the front-line teachers, so as to help them realize the deficiencies of the teaching materials and make appropriate adjustments to the teaching materials according to the actual teaching situation.

\section{Limitation of the Study}

The main shortcomings of this study are as follows: 
1) The number of teachers interviewed is small, and all of them are from the same school.

2) The interviewed teachers' gender and educational background are unbalanced.

3) Students' questionnaires are not designed scientifically enough because of researcher's limited abilities.

4) Students were not interviewed and their final feedback is not collected.

Follow-up studies will improve these aspects.

\section{Acknowledgments}

This paper is one of the research achievements of "Research on POA Teaching Mode Guided by ETIC and Relying on Going Global Course" (No.2021YYJG053) supported by Research and Practice Project of English Teaching Reform in Colleges and Universities of Hebei Province in 2021. This paper is also supported by Higher Education Teaching Reform Research and Practice Project of Hebei Province (No. 2020GJJG623).

\section{References}

Cheng, X. T. (2002). English teaching material analysis and design. Beijing: Foreign Language Teaching and Research Press.

Hu, W. (2017). Analysis of Contemporary College English Intensive Reading based on Cunningsworth evaluation framework. Campus English, 32, 14-15.

Jia, F., \& Shen, Y. X. (2020). Evaluating Going Global in the framework of POA: from the perspective of teachers. Foreign Language Education in China, 3(3), 19-26.

Li, C. J. (2018). Going Global. Beijing: Foreign Language Teaching and Research Press.

Qiu, L. (2017). Research on the use of POA teaching materials: process of selecting and transforming input materials and evaluation. Foreign Language Education in China, 10(2), 32-39.

Wei, W. L., \& Wang, G. D. (2020). Review and Reflection on the Research of College English Textbooks in China in the 21st Century. English Teacher, 3, 120-123.

Wen, Q. F. (2017). A theoretical framework for using and evaluating POA-based teaching materials. Foreign Language Education in China, 10(2), 17-23.

Xu, J. F., \& Xiao, C. (2011). Evaluation of the teaching content of College English Listening Textbook. Foreign Language World, 2, 39-45.

Zheng, Z. H. (2012). Corpus-based vocabulary evaluation of English reading textbooks. Foreign Language Research, 5, 56-63.

Zhu, Q., \& Xu, J. F. (2014). Layout, reproduction and practice of vocabulary and grammar in excellent foreign English textbooks. Foreign Language Learning Theory and Practice, 4, 25-33.

\section{Appendix A}

\section{Interview problem for teachers}

Part one: questions related to teachers' background information

1. What is your professional title and educational background? How long have you been teaching?

Part two: questions related to the evaluation of Going Global as a whole

2. How do you evaluate Going Global as a whole? What are the characteristics of this textbook?

Part three: questions related to the two dimensions: "appropriate productive objectives" and "effective enabling activities"

3. How do you think the difficulty of Going Global (Elementary) is for freshmen?

4. Can Going Global stimulate your willingness and interest in teaching and students' willingness and interest in learning?

5. Does Going Global provide clear goals? Are the teaching objectives of each unit refined into small objectives? If so, are there any internal relationships among these goals? If not, what do you think should be improved?

6. Can the content, language and discourse structure of the textbook help students achieve its set goals?

7. Is there increasing trend on difficulty for single book, or for the series of books? 
8. Whether does the design of Going Global help students complete the set objectives and tasks step by step?

9. Does Going Global provide diversified activities in listening, speaking, reading, writing and translating?

Part four: open supplementary questions.

10. Apart from the above questions, do you have any comments or supplements on Going Global?

\section{Appendix B}

\section{Table B Questionnaire for students}

\begin{tabular}{|c|c|c|}
\hline Indicator & Problem & Choices \\
\hline \multirow[b]{2}{*}{ engagement } & $\begin{array}{l}\text { 1. What do you think of Going } \\
\text { Global at the first sight? }\end{array}$ & $\begin{array}{l}\text { A. So interesting that I can't help reading it. } \\
\text { B. Interesting. It's a little more novel than the previous textbooks. } \\
\text { C. Generally speaking, there is not so much change compared to previous textbooks. } \\
\text { D. Has no feeling. }\end{array}$ \\
\hline & $\begin{array}{l}\text { 2. What do you think of the book } \\
\text { when further exploring it with } \\
\text { the help of teachers? }\end{array}$ & $\begin{array}{l}\text { A. Tasks are set in real workplace atmosphere, and the types of tasks are diversified, } \\
\text { which makes me actively participate in it involuntarily. } \\
\text { B. Colorful and practical tasks trigger my interest to participate than before to some } \\
\text { degree. } \\
\text { C. Going Global is more interesting than the previous textbooks, but still couldn't } \\
\text { motivate me to participate. } \\
\text { D. It fails to arouse your enthusiasm for participation. }\end{array}$ \\
\hline \multirow{2}{*}{$\begin{array}{l}\text { sense of } \\
\text { acquisition }\end{array}$} & $\begin{array}{l}\text { 3. What's your feeling after unit } \\
\text { learning? }\end{array}$ & $\begin{array}{l}\text { A. Because the completion of the sub-goal of each unit is facilitated by the completion of } \\
\text { more refined small goals, I have clarity of thought about what and how I will do. When } \\
\text { finishing studying the unit, I have a great sense of accomplishment. } \\
\text { B. Each unit clearly lists the goals achieved, which is more objective than the previous } \\
\text { English study. } \\
\text { C. I think that each unit has many goals, but fails to clarify the logical relationship } \\
\text { among them, so I feel confused. } \\
\text { D. Seems to have not learned practical language skills. }\end{array}$ \\
\hline & $\begin{array}{l}\text { 4. What's your feeling after the } \\
\text { whole book learning? }\end{array}$ & $\begin{array}{l}\text { A. The whole textbook has } 4 \text { cases which respond to } 4 \text { tasks. The completion of each } \\
\text { task requires comprehensive coordination of various skills, so I feel that my core } \\
\text { competence has been improved after learning. } \\
\text { B. Compared with the previous isolated listening, speaking, writing, reading and } \\
\text { translation skills, I feel my communication skills have been improved. } \\
\text { C. Communication ability seems to be improved, but the overall feeling is that I am just } \\
\text { busy with dealing with various tasks finishing. } \\
\text { D. It's not clear which skills have been improved. }\end{array}$ \\
\hline
\end{tabular}

\section{Copyrights}

Copyright for this article is retained by the author(s), with first publication rights granted to the journal.

This is an open-access article distributed under the terms and conditions of the Creative Commons Attribution license (http://creativecommons.org/licenses/by/4.0/). 